\title{
A comparative survey of genetic diversity among a set of Caricaceae accessions using microsatellite markers
}

\author{
Samik Sengupta ${ }^{2}$, Basabdatta Das ${ }^{1}$, Manoj Prasad ${ }^{3}$, Pinaki Acharyya ${ }^{2}$ and Tapas Kumar Ghose ${ }^{\text {** }}$
}

\begin{abstract}
A preliminary survey of genetic diversity among 34 commercially popular Carica papaya cultivars from India and abroad, 6 accessions of Vasconcellea species and 1 accession of Jacaratia spinosa, was done using 20 simple sequence repeat (SSR) markers. The SSR profiles were used to find out total number of alleles, null and rare alleles, Polymorphism Information Content (PIC) values and to calculate similarity matrix using Jaccard's coefficient. The subsequent dendrogram was made by unweighted pair-group method of arithmetic average (UPGMA) and neighbor-joining method. Based on these parameters a comparison was made between the Indian papaya cultivars and the rest of the accessions. All the markers showed polymorphism and a total of 140 alleles were identified. The average number of alleles was 7 alleles/locus. Categorically the Vasconcellea and Jacaratia species had 54 alleles, the 7 non-Indian Carica papaya accessions had 70 and the 27 Indian accessions had 102 alleles. The average PIC value was 0.735 per marker. A total of 37 rare alleles were identified. Jacaratia spinosa had 17 rare alleles. Nineteen null alleles were detected among the Carica papaya accessions. A Carica papaya accession from South Africa, Hortus Gold had 5 null alleles. The genetic similarity among the accessions ranged from $7 \%$ to $67 \%$. In the dendrogram, the Vasconcellea and Jacaratia spinosa accessions separated as a distinct cluster from the rest of the Carica papaya accessions. The study indicated that the accessions of Indian Carica papaya cultivars included in this survey are genetically more diverse than the non-Indian Carica papaya cultivars.
\end{abstract}

Keywords: Caricaceae; Carica papaya; Genetic diversity; SSR

\section{Background}

The family Caricaceae consists of six genera of herbaceous, shrubby or arborescent dicotyledonous plants having a common phylogenetic origin with Brassicaceae, and consequently with the completely sequenced model plant Arabidopsis (Bremer et al. 1998, Rodman et al. 1996). From the perspective of human consumption Carica and Vasconcellea are the two most important genera within Caricaceae (Badillo 1993 and 2000). Vasconcellea grows at a height of $1000 \mathrm{~m}$ and higher, above sea level, mostly in wild humid forests, but are also semi-domesticated or tolerated in local gardens in the highlands of South America. The only Vasconcellea species cultivated in an intensive way, although only in Ecuador and New Zealand is the

\footnotetext{
*Correspondence: tapasghoselab@gmail.com

'Division of Plant Biology, Bose Institute, Main Campus, 93/1 A.P.C. Road, Kolkata, West Bengal 700009, India

Full list of author information is available at the end of the article
}

cultivar Babaco ( $V . \times$ heilbornii 'Babaco', Villarreal et al. 2003). On the other hand Carica papaya (commonly known as papaya) originated and was subsequently domesticated in Central America and has hundreds of cultivars spread over 50 countries around the world (Purseglove 1974; Storey 1969; Kulsekaran 1984; Nakasone and Paull, 1998; FAO 2009). Wide range of germplasm variability, rapid development and copious production of seeds have made papaya a potentially valuable fruit tree model crop for genomic and genetic diversity analysis (Liu et al. 2004; Yu et al. 2008). Some 2.5 billion kilograms of papaya are produced annually in India in the states of Andhra Pradesh, Assam, Bihar, Gujarat, Karnataka, Maharashtra, Manipur, Meghalaya, Orissa, Tamil Nadu, Uttar Pradesh and West Bengal. It is eaten fresh or cooked and is processed into pickles, jams, candies, fruit drinks and juices. Papain, an enzyme purified from papaya latex, is extracted for export. The 
enzyme is used in medicine and textile industries, breweries, leather processing and in meat tenderizing. Ram et al. (1985) classified the popular Indian papaya cultivars like Coorg Honey Dew, Washington, CO1, CO2, PusaDwarf, Surya etc. into various groups like primitive genotypes, traditional genotypes, minor genotypes, local adaptive genotypes and principal genotypes. The germplasms of Carica show considerable phenotypic variation in plant stature, length of juvenile period, fruit size, fruit shape, flesh color, flavor and sweetness, stamen carpelloidy, and carpel abortion (Drew et al. 1998; Manshardt and Wenslaff, 1989). Although India has a vast array of indigenous papaya cultivars (Ram 2005), reports of systematic collection, conservation, documentation and evaluation of different germplasms and study of their inherent genetic diversity are limited.

Analysis of Simple Sequence Repeat (SSR) polymorphism is a popular molecular tool for surveying genetic diversity (Xiao et al. 1996). There are plenty of reports on analysis of Caricaceae genotypes using SSR markers. Asudi et al. (2010) collected 42 papaya germplasm from Coast, Nyanza, Western, Rift Valley, Eastern and Central provinces of Kenya, characterized them morphologically and also assessed their genetic diversity using 7 SSR markers. They found that number of alleles across the seven loci ranged from 8 to 18 with an average of 11.93 alleles/locus. The polymorphism information content (PIC) varied from 0.75 to 0.852 with an average of 0.81 . Oliveira et al. (2010a and 2010b) identified 20 polymorphic microsatellite primers which they used for marker assisted selection of 83 papaya lines and identified an average of 3.18 alleles per primer. Kyndt et al. (2006) analysed a set of 103 Vasconcellea accessions and some individuals of the related genera Carica and Jacaratia with the help of 10 chloroplast and 9 nuclear SSR markers. Six of the chloroplast and seven nuclear SSRs showed polymorphism. Other molecular markers like random amplified polymorphic DNA (RAPD) (Sondur et al. 1996) and amplified fragment length polymorphism (AFLP) (Ma et al. 2004) were used to construct papaya genetic maps. In 2001, Ming et al. (2001) reported the construction of a papaya bacterial artificial chromosome (BAC) library which contained 39,168 clones from the Hawaiian papaya cultivar "Sun Up". Chun et al. (2006) have analyzed the microsatellite content, repeat element composition and protein-coding regions from the BAC library of the hermaphrodite papaya cultivar SunUp. Later, Eustice et al. (2008) mined 28.1 Mb of BAC end sequences, 5.8 $\mathrm{Mb}$ of complementary DNA, and $1.6 \mathrm{Mb}$ of random genomic sequences and identified 938 SSR markers. A major study on papaya diversity in India was done by Singh et al. (2006). They collected and studied 21 accessions of papaya comprising of Indian and exotic cultivars and identified 2 excellent varieties 'Pusa Delicious' and ' $\mathrm{CO} 7$ ' with good growth attributes and physicochemical characters of the fruits. Given the number of papaya cultivars available in India, more investigations into papaya genetic diversity are required to facilitate unambiguous identification of the various germplasms and their protection under the trade related intellectual property rights (TRIPS) of the World Trade Organization (WTO). This study surveyed the inherent genetic diversity of 34 commercially popular Carica papaya cultivars and seven species of Caricaceae genotypes using 20 SSR markers. The SSR profiles were used for comparisons between the accessions of Indian and non-Indian papaya cultivars. Statistical calculations were used for grouping the accessions into various clusters in order to unambiguously identify and to establish a relationship among the accessions.

\section{Results}

\section{Analysis of SSR profiles}

\section{Number of alleles}

Table 1 summarizes the analyses of SSR profiles of 41 accessions using 20 SSR markers. Figure 1 shows a SSR profile depicting rare and null allele. The minimum and maximum molecular weight among the alleles, number of rare alleles, number of null alleles, total number of alleles and PIC values for each marker are given in table. The alleles were scored based on the molecular weight. The reference molecular weight for each marker (as in the accession SunUp) is also shown in Table 1. All the markers showed polymorphism and a total of 140 alleles were identified from the experimental set of Caricaceae accessions. The number of alleles ranged from 2 in SP4 and SP8 to 11 in SP1, SSPA1, SSPA5 and SSPA8. The average number of alleles was 7 alleles/ locus. The average number of alleles for markers amplifying both dinucleotide and trinucleotide repeats, was also 7. Categorically the total number of alleles for 6 Vasconcellea and 1 Jacaratia accessions was 54 with an average of 2.7 alleles/locus. The smallest number of alleles identified was 1 each in the markers SP4 and SP8. The highest number of alleles in this category was 5, detected from the profile of the marker SSPA8. The average number of alleles for markers amplifying dinucleotide repeats (2.9 alleles/locus) was more than that for trinucleotide repeats (2.5 alleles/locus). The total number of alleles for the 7 non-Indian Carica papaya accessions was 70 with an average of 3.5 alleles/locus. The smallest number of alleles identified was 2 each in the profiles of the markers SP2, SP4, SP7, SP8, SP10 and SSPA2. The highest number of alleles in this category was 6, identified from the profile of the markers SP1 and SSPA5. The average number of alleles from markers amplifying dinucleotide repeats (3.57 alleles/locus) was more than that for trinucleotide repeats (3.33 alleles/ locus). The total number of alleles for the 27 Indian 
Table 1 Minimum and maximum molecular weight among the alleles, Rare alleles (R), null alleles (N), alleles and PIC values for each marker

\begin{tabular}{|c|c|c|c|c|c|c|c|c|c|c|c|c|c|}
\hline \multirow[t]{2}{*}{ Marker } & \multirow[t]{2}{*}{ Min MW } & \multirow[t]{2}{*}{ Max MW } & \multirow{2}{*}{$\begin{array}{l}\text { Sun Up } \\
\text { MW }\end{array}$} & \multirow[t]{2}{*}{$\mathbf{R}$} & \multirow[t]{2}{*}{$\mathbf{N}$} & \multicolumn{4}{|c|}{ Number of alleles } & \multicolumn{4}{|c|}{ PIC values } \\
\hline & & & & & & Total & V\&J & FA & IA & Total & V\&J & FA & IA \\
\hline SP1 & 415.405 & 424.341 & 489 & 1 & 1 & 11 & 3 & 6 & 9 & 0.919 & 0.571 & 0.836 & 0.894 \\
\hline SP2 & 125.854 & 543.174 & 678 & 4 & 3 & 10 & 3 & 2 & 9 & 0.929 & 0.448 & 0.632 & 0.941 \\
\hline SP3 & 341.25 & 445.714 & 656 & 2 & 0 & 9 & 3 & 5 & 7 & 0.909 & 0.612 & 0.775 & 0.877 \\
\hline SP4 & 165 & 170 & 594 & 0 & 0 & 2 & 1 & 2 & 2 & 0.499 & 0 & 0.489 & 0.482 \\
\hline SP5 & 246.263 & 270.884 & 611 & 1 & 2 & 7 & 3 & 4 & 5 & 0.810 & 0.571 & 0.795 & 0.796 \\
\hline SP6 & 385 & 409.062 & 698 & 1 & 1 & 6 & 3 & 3 & 4 & 0.728 & 0.448 & 0.448 & 0.684 \\
\hline SP7 & 168.988 & 176.02941 & 717 & 1 & 1 & 6 & 3 & 2 & 3 & 0.668 & 0.571 & 0.469 & 0.559 \\
\hline SP8 & 127.49 & 135.64 & 603 & 0 & 0 & 2 & 1 & 2 & 2 & 0.492 & 0 & 0.489 & 0.384 \\
\hline SP9 & 180.976 & 196.77975 & 764 & 2 & 0 & 5 & 3 & 3 & 3 & 0.696 & 0.571 & 0.571 & 0.658 \\
\hline SP10 & 232.555 & 485.333 & 701 & 1 & 1 & 6 & 3 & 2 & 4 & 0.715 & 0.448 & 0.591 & 0.622 \\
\hline SSPA1 & 425.321 & 488.296 & 374 & 1 & 1 & 11 & 3 & 5 & 9 & 0.884 & 0.612 & 0.734 & 0.862 \\
\hline SSPA2 & 272.5 & 389.285 & 348 & 2 & 1 & 6 & 3 & 2 & 3 & 0.581 & 0.571 & 0.244 & 0.448 \\
\hline SSPA3 & 159.372 & 181.415 & 156 & 2 & 0 & 7 & 4 & 3 & 4 & 0.652 & 0.591 & 0.571 & 0.614 \\
\hline SSPA4 & 195.035 & 206.143 & 203 & 1 & 0 & 6 & 3 & 4 & 5 & 0.745 & 0.224 & 0.693 & 0.652 \\
\hline SSPA5 & 402.068 & 482.090 & 438 & 6 & 0 & 11 & 2 & 6 & 7 & 0.862 & 0.244 & 0.816 & 0.806 \\
\hline SSPA6 & 117.426 & 125.800 & 124 & 1 & 0 & 5 & 2 & 3 & 4 & 0.658 & 0.244 & 0.612 & 0.529 \\
\hline SSPA7 & 267.75 & 615.517 & 290 & 2 & 2 & 7 & 2 & 3 & 6 & 0.731 & 0.244 & 0.571 & 0.661 \\
\hline SSPA8 & 264.102 & 363.545 & 326 & 5 & 2 & 11 & 5 & 5 & 8 & 0.861 & 0.775 & 0.816 & 0.817 \\
\hline SSPA9 & 89.166 & 110.379 & 107 & 2 & 1 & 5 & 2 & 4 & 3 & 0.589 & 0.244 & 0.612 & 0.524 \\
\hline \multirow[t]{3}{*}{ SSPA10 } & 195.238 & 215.25 & 202 & 2 & 3 & 7 & 2 & 4 & 5 & 0.765 & 0.244 & 0.734 & 0.696 \\
\hline & & & Total SUM & 37 & 19 & 140 & 54 & 70 & 102 & 14.701 & 8.244 & 12.510 & 13.517 \\
\hline & \multicolumn{3}{|c|}{ Average AVERAGE } & 1.85 & 0.95 & 7 & 2.7 & 3.5 & 5.1 & 0.735 & 0.412 & 0.625 & 0.675 \\
\hline
\end{tabular}

MinMW Minimum molecular weight of the alleles in that locus, Max MW Maximum molecular weight of the alleles in that locus, SunUp MW,

Molecular weight of the allele obtained from the reference genotype SunUp, V\& J accessions of Vasconcellea and Jacaratia, FA foreign Carica papaya accessions,

IA Indian Carica papaya accessions.

Carica papaya accessions was 102 with an average of 5.1 alleles/locus. The smallest number of alleles identified was 2 in SSR profiles of the marker SP8. The highest number of alleles in this category was 9 from the profiles of the markers SP1, SP2 and SSPA1. Contrary to the others, in this category, the average number of alleles from the markers amplifying dinucleotide repeats (4.93 alleles/locus) was less than that for trinucleotide repeats (5.5 alleles/locus).

\section{Polymorphism Information Content (PIC) values}

The PIC values, which denote allelic diversity and frequency among germplasms, had an average value of 0.735/marker. The range of PIC values was 0.492 in SP8 to 0.929 in SP2. Categorically average PIC value for the Vasconcellea accessions was 0.412 /marker with a range of 0.244 for the markers SSPA5, SSPA6, SSPA7, SSPA9 and SSPA10 to 0.775 for the marker SSPA8. For the non-Indian papaya accessions the average PIC value was $0.625 /$ marker and range of PIC values was 0.245 for the marker SSPA2 to 0.837 for SP1. The Indian papaya accessions had an average PIC value of $0.676 /$ marker. The range of PIC values was 0.384 for the marker SP8 to 0.941 for SP2. From the PIC values it was evident that the allelic diversity was the highest among the Indian papaya accessions. The average PIC value of the

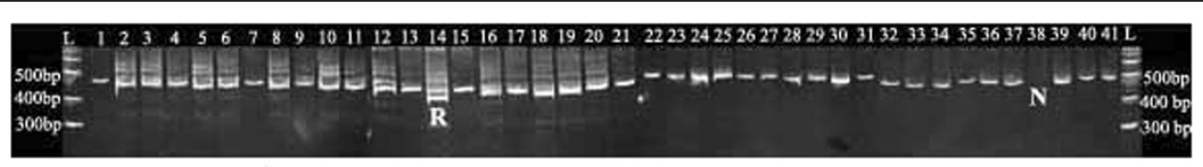

SSR profile of marker SSPA1. Lane no. 14 designated as "R" show a rare allele and lane no. 38 designated as "N" show a null allele

Figure $1 \mathrm{Gel}$ image showing the presence of rare and null allele. 
markers amplifying dinucleotide repeats was 0.727 . The same for trinucleotide repeat containing markers was 0.753. This trend was maintained in all the other categories except in case of the Vasconcellea accessions where the average PIC value for the trinucleotide repeat amplifying markers was less than average PIC value for the dinucleotide repeat amplifying markers. Analysis of Variance test (ANOVA test) was done to test whether the means of the PIC values for the total set of germplasms, and for the three categories (Indian and non Indian Carica papaya accessions and the accessions of Vasconcellea species and Jacaratia spinosa) were significantly different or not. The result of the test is tabulated in Table 2. From the ANOVA test it was found that the observed $\mathrm{F}$ value exceeded the tabulated $\mathrm{F}$ value at $1 \%$. Hence the null hypothesis that the means PIC values of the three categories i.e. Indian and nonIndian Carica papaya accessions and the accessions of Vasconcellea species and Jacaratia spinosa were same, was rejected. From the calculated critical difference it was observed that the average PIC values were significantly different when comparison was made between Vasconcellea sp. and Jacaratia spinosa accession and Indian accessions. The same applied when a comparison was made between Vasconcellea sp. and Jacaratia spinosa accession and non-Indian accessions. But the PIC values between the accessions of Indian and nonIndian Carica papaya accessions were not significantly different.

\section{Rare alleles}

As per the definition of rare alleles by Jain et al. (2004) a total of 37 rare alleles were identified from 18 polymorphic loci with an average of 1.85 rare alleles per loci. A rare allele is shown in the gel image given in Figure 1. Average rare alleles from the dinucleotide repeat amplifying markers was 2 and that from the trinucleotide repeat amplifying marker was 1.5 . The highest number of rare alleles (8 rare alleles) was identified in the profile of SSPA5 followed by SSPA 8 (7 rare alleles) and SSPA 2 (5 rare alleles). Among the Caricaceae accessions, Jacaratia spinosa had the maximum number of rare alleles (17 rare alleles) almost one for each of the 20 markers used. Four Vasconcellea accessions shared amongst themselves 5 rare alleles. Vasconcellea quercifolia had 2 and $V$. pubescens, $V$. goudotiana and V. microcarpa had 1 rare allele each. Among the Carica papaya cultivars, five non-Indian accessions had 8 rare alleles and thirteen Indian accessions had 7 rare alleles. Among the non-Indian accessions Taiwan, Solo109 and Waimanalo had 2 while Kapoho and Taiwan Red Lady had 1 rare allele each. Among the Indian accessions Yellow Indian, Pusa Giant, Ranchi, Coorg Honey Dew, Surya, Madhu and RT2 each had 1 rare allele.

\section{Null alleles}

As per the definition of null alleles by Callen et al. (1993) 19 null alleles were detected from 12 polymorphic loci. A null allele is shown in the gel image given in Figure 1. Average null alleles identified for the dinucleotide repeat amplifying markers was 0.79 alleles/marker and that for the trinucleotide repeat amplifying markers was 1.33 alleles/marker. The highest number of null alleles (3 alleles each) were identified in the profiles of SP2 and SSPA10 followed by SP5, SSPA7 and SSPA8 (2 alleles each). In this study no null alleles were detected in the 6 Vasconcellea and 1 Jacaratia accessions. The non-Indian Carica papaya accession from South Africa, Hortus Gold generated 5 null alleles. Waimanalo an accession from Hawaii and Taiwan Red Lady, a F1 hybrid of the Tainung series had 2 null alleles each. Another accession of the same series, Taiwan had one null allele. The Indian papaya accessions Yellow Indian, Coorg Honey Dew, Ranchi, Surya, Madhu, Orissa local, $\mathrm{CO} 1, \mathrm{CO} 7$ and PAU selection had one null allele each.

\section{Clustering of the Caricaceae accessions}

The dendrogram given in Figure 2 was made from genetic similarity values. The strength of dendrogram nodes was estimated with a bootstrap analysis using 1000 permutations. The similarity among the Caricaceae accessions ranged from $7 \%$ to $67 \%$ and they were divided into 2 major clusters "A" and "B" and 7 sub clusters. At $7 \%$ level of similarity two distinct major clusters "A" and "B" were present. Major cluster "A" included 6 accessions of the 6 different Vasconcellea species along with the accession of the related species Jacaratia spinosa. Within this cluster, two accessions of Vasconcellea goudotiana and Vasconcellea stipulata were 67\% similar amongst themselves. The second major cluster "B" consisted of the rest of the 34 Carica papaya accessions grouped into various clusters and sub clusters at higher levels of similarity.

Within major cluster "B", at about $11.9 \%$ level of similarity, the South African accession Hortus Gold segregated

Table 2 Analysis of variance table for polymorphism information content values

\begin{tabular}{llllll}
\hline Source of variation & $\begin{array}{l}\text { Sum of } \\
\text { squares }\end{array}$ & $\begin{array}{l}\text { Degrees of } \\
\text { freedom }\end{array}$ & $\begin{array}{l}\text { Mean sum } \\
\text { of squares }\end{array}$ & Observed & Tabulaed \\
\hline Between markers & 30.5023 & 19 & 1.6054 & 44.5394 & 1 (at 5\%) \\
Within markers (error) & 2.1626 & 60 & 0.036 & 1 (at 1\%) \\
\hline
\end{tabular}




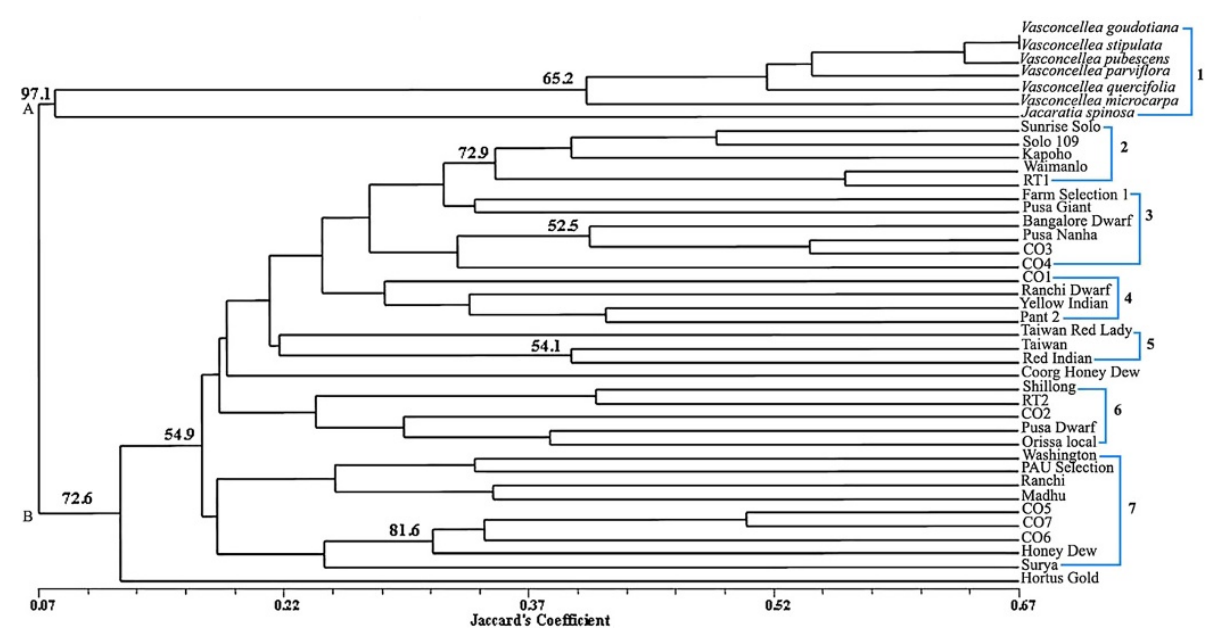

Figure 2 Dendrogram of 41 Caricaceae accessions based on Jaccaard's genetic similarity coefficient.

out and the rest of the 33 Caricaceae accessions underwent segregation at $16 \%$ level of similarity and differentiated into sub clusters 2 to 7 . Sub cluster 2 included the Hawaiian accessions of Sunrise Solo, Solo109, Kapoho and Waimanalo along with the Indian accession RT1. Among these the highest genetic similarity of about $54.5 \%$ was observed between the accessions Waimanalo and RT1. Sub cluster 3 included the accessions Farm Selection 1, Pusa Giant, Pusa Nanha, Bangalore Dwarf, CO3 and CO4. The highest genetic similarity of about $52 \%$ was observed between $\mathrm{CO} 3$ and $\mathrm{CO} 4$. Sub cluster 4 included the accessions CO1, Ranchi dwarf, Yellow India and Pant 2 with the highest genetic similarity of $38 \%$ between the last two accessions. Sub cluster 5 included the non-Indian accessions Taiwan Red Lady and Taiwan along with the Indian accession Red Indian. The highest genetic similarity of about 38\% was observed between Taiwan and Red Indian. Sub cluster 6 included the Indian accessions Shillong, RT2, CO2, Pusa Dwarf, and Orissa Local with the highest genetic similarity of about 38\% between Shillong and RT2. Sub cluster 7 included the Indian accessions Washington, PAU Selection, Ranchi, Madhu, CO5, CO6, CO7, Honey Dew and Surya. The highest genetic similarity of about $50 \%$ was observed between CO5 and CO7.

\section{Discussion}

The inherent genetic diversity of this set of Caricaceae accessions was apparent from the analysis of the SSR profiles and from the dendrogram where all the accessions had unambiguously separated. In general all the SSR markers used in this study produced clear and consistent amplification profiles. Stutter bands, which were minor products amplified in PCR and had lower intensity than the main allele because they normally lacked or had extra repeat units; (Walsh et al. 1996) were also present in the profiles of most of the markers used. Rare alleles as described by Jain et al. (2004) was detected from within this set of accessions. Null alleles were present probably due to mutations in the binding region of one or both of the microsatellite primers, which inhibited primer annealing (Callen et al. 1993). The average number of SSR alleles for the Indian and non-Indian Carica papaya accessions were 6 alleles per locus. This number was much higher than that reported for average number of alleles by Oliveira et al. (3.18 alleles per locus, 2010a) and was much smaller than the study by Asudi et al. (2010) which reported 11.93 alleles/locus. Although this study was just an overview of the inherent genetic diversity, the Indian Carica papaya accessions produced more alleles per SSR marker (5.1 alleles/locus) as compared to those generated from the non-Indian Carica papaya accessions (3.5 alleles/locus) and the accessions of Vasconcellea sp. and Jacaratia spinosa (2.7 alleles/ locus). Average PIC value was the highest among the Indian papaya accessions. However there was no significant difference of PIC values between the Indian and the non-Indian accessions. Twenty two out of the thirty seven rare alleles were detected in the seven accessions of Vasconcellea sp and Jacaratia spinosa. Therefore on an average 3.14 rare alleles per accession was detected in the former group as compared with 0.44 rare alleles per accession in case of the Carica papaya accessions. The accessions of Jacaratia spinosa and Vasconcellea sp segregated as a single cluster from the Carica papaya accessions with only $7 \%$ genetic similarity. Therefore in tune with the taxonomic descriptions of Badillo (2000), our findings also indicated that Jacaratia spinosa and Vasconcellea $s p$ are distinctly different from Carica $p a-$ paya. The same was reported by Van Droogenbroeck et al. (2002) while using Amplified Fragment Length 
Polymorphism (AFLP) to study genetic relationship among Caricaceae accessions. It was indicated by Droogenbroeck et al. (Van Droogenbroeck et al. 2002) that the Carica papaya accessions were very distinct from Vasconcellea on the basis of results of cluster analysis and bootstrap analysis. Moreover, they reported a higher level of similarity between Vasconcellea accessions and Jacaratia spinosa. Similar conclusion was also apparent from the dendrogram derived from our study. During the analysis of genetic diversity of Carica papaya using AFLP, Kim et al. (2002) found that Carica papaya shared the least genetic similarity with other Caricaceae accessions. The Carica papaya accessions from our study were also distant from the Vasconcellea and Jacaratia accessions. However the Indian accessions of Carica papaya in this study had more allelic diversity as per their SSR profiles. Among the 34 Carica papaya accessions, Hortus Gold a clone from South Africa with 5 null alleles was distinctly diverse from the rest of the 33 accessions having only 13\% genetic similarity. Further insight into the allelic nature of other loci of this accession and its comparison with other Carica papaya accessions will make an interesting subject for examination of genetic diversity in future studies. Out of the 34 Carica papaya accessions, 19 were dioecious and 15 were gynodioecious. It was found during the study that the dioecious group of accessions shared amongst them a total of 101 alleles with an average of 5.05 alleles/marker. The gynodioecious group of accessions on the other hand had a total of 96 alleles amongst them with an average of 4.8 alleles/marker. The Indian accessions were mostly dioecious whereas all the non-Indian accessions were gynodioecious except for Hortus Gold, which was dioecious.

In the dendrogram the accessions Sunrise Solo, Solo 109, Kapoho and Waimanalo were grouped into the same sub cluster. In Hawaii, the parentage of most of the papaya cultivars was based on the cultivar Solo, which was introduced from Barbados and Jamaica in 1911. Solo gave rise to several varieties, like Sunrise, Sunset, Solo 109 and Kapoho. Sunrise Solo, one of the accessions in this study, was an inbred reddish orange strain resulting from a cross between "Pink Solo" with the yellow fleshed farmer' selection "Kariya solo" (Hamilton and Ito, 1968). In the dendrogram these accessions were situated in close proximity. According to Ram (2005), the fruit morphology of Kapoho and Waimanalo was almost similar but genetic difference between them was high. As can be seen from the dendrogram, (Figure 2) Kapoho and Waimanalo was only about $38 \%$ similar genetically. Waimanalo was a genotype from Florida and was a selection from the cross between $5^{\prime}$ Solo and Betty.

In the same dendrogram (Figure 2) the accessions of Coimbatore varieties (CO1-CO7) were included in separate sub clusters. These accessions were developed in the
South Indian state of Tamil Nadu and were bred in a span of 14 years by various workers and had distinct sex forms, fruit characteristics and papain yield. Principal genotype $\mathrm{CO} 1$ was a selection from the genotype Ranchi and $\mathrm{CO} 2$ was a selection from Peradeniya, a genotype from Sri Lanka. CO3 was developed from a cross between $\mathrm{CO} 2$ and Sunrise Solo and $\mathrm{CO} 4$ was the result of a cross between the genotypes $\mathrm{CO} 1$ and Washington. In the same manner the three accessions of the Pusa series; Pusa Nanha, Pusa Giant and Pusa Dwarf were also found in different sub clusters. Developed at IARI, New Delhi during 1966 to 1982 (Ram, 2005), Pusa Dwarf was an original selection from Pusa Giant and was very popular in Eastern Uttar Pradesh and Northern Bihar. Pusa Giant was selected to withstand high wind velocities in various parts of the country. Pusa Nanha was a dwarf mutant evolved by gamma irradiation (Ram and Sharma, 1996). Both Pusa Nanha and PusaDwarf have short plant height but differences in their origin had made them genetically diverse. The accessions pairs Ranchi, Ranchi Dwarf and Honey Dew, Coorg Honey Dew also segregated into different sub clusters. Ranchi was an accession found in the state of Jharkhand, India. It has a large number of segregating populations which were found in Northern India. Ranchi Dwarf was a selection from Ranchi. Honey Dew was bred in the South Indian state of Karnataka and Coorg Honey Dew was a selection done at Chethalli, Coorg in 1959. According to Ram (2005) both Ranchi and Honey Dew are "Minor genotypes" i.e. plants grown from seeds of selected fruits of the traditional cultivars. Both Ranchi Dwarf and Coorg Honey Dew were categorized by Ram (2005) as being "Local adaptive genotype" which was described as phenotypic selection having better plant type, quality and productivity from within the minor genotypes. The "Local adaptive genotypes" are more suitable for growing in special agro-climatic zones. As was evident from the dendrogram this adaptation caused enough genotypic modifications so as to segregate the accessions into different clusters.

\section{Conclusions}

In view of the results obtained it was perceptible that, at least for the loci amplified by the markers and for the set of accessions used, the Indian Carica papaya accessions had more allelic diversity than the non-Indian cultivars and the Caricaceae species included in this study. However there was no significant difference of average PIC values between the Indian and the non-Indian accessions. Although Vasconcellea and Jacaratia are distant from Carica papaya in the evolutionary perspective yet there must be some genotypic and phenotypic similarity as they had been classified under the same family, Caricaceae. At least in case of the loci amplified by the 20 markers used in this study, may be such kind of similarity 
Table 3 Category, cultivar name, source and number of accessions used for this study

\begin{tabular}{|c|c|c|c|c|}
\hline \multicolumn{5}{|c|}{ Indian Carica papaya cultivars } \\
\hline Category Ram (2005) & Cultivar name & Sex form & Source & Number of accessions \\
\hline Local adaptive genotype & Ambasa Local (RT2) & Dioecious & ICAR, Tripura & 1 \\
\hline Local adaptive genotype & Bangalore Dwarf & Dioecious & Pvt. seed company & 1 \\
\hline Local adaptive genotype & Coorg Honey Dew & Gynodioecious & ICAR, Tripura & 1 \\
\hline Local adaptive genotype & Farm Selection -1 & Gynodioecious & Pvt. seed company & 1 \\
\hline Local adaptive genotype & Madhu & Gynodioecious & Pvt. Seed company & 1 \\
\hline Local adaptive genotype & Orissa local & Dioecious & OUAT & 1 \\
\hline Local adaptive genotype & Pant 2 & Dioecious & $\| H R$ & 1 \\
\hline Local adaptive genotype & PAU Selection & Dioecious & $\| H R$ & 1 \\
\hline Local adaptive genotype & Ranch Dwarf & Dioecious & Pvt. Seed company & 1 \\
\hline Local adaptive genotype & Shillong & Dioecious & $\| H R$ & 1 \\
\hline Local adaptive genotype & RT1 & Dioecious & ICAR, Tripura & 1 \\
\hline Local adaptive genotype & Washington & Dioecious & $\| \mathrm{HR}$ & 1 \\
\hline Minor genotype & Honey Dew & Gynodioecious & ICAR, Tripura & 1 \\
\hline Minor genotype & Ranchi & Dioecious & Pvt. seed company & 1 \\
\hline Principal genotype & CO 1 & Dioecious & ICAR, Tripura & 1 \\
\hline Principal genotype & $\mathrm{CO} 2$ & Dioecious & TNAU & 1 \\
\hline Principal genotype & $\mathrm{CO} 3$ & Gynodioecious & TNAU & 1 \\
\hline Principal genotype & $\mathrm{CO} 4$ & Dioecious & TNAU & 1 \\
\hline Principal genotype & $\operatorname{CO} 5$ & Dioecious & TNAU & 1 \\
\hline Principal genotype & $\mathrm{CO} 6$ & Dioecious & Pvt. seed company & 1 \\
\hline Principal genotype & CO 7 & Gynodioecious & TNAU & 1 \\
\hline Principal genotype & Pusa Dwarf & Dioecious & $\| \mathrm{HR}$ & 1 \\
\hline Principal genotype & Pusa Giant & Dioecious & $\| H R$ & 1 \\
\hline Principal genotype & Pusa Nanha & Dioecious & $\| H R$ & 1 \\
\hline Principal genotype & Red Indian & Gynodioecious & Pvt. seed company & 1 \\
\hline Principal genotype & Surya & Gynodioecious & $\| H R$ & 1 \\
\hline Principal genotype & Yellow India & Gynodioecious & Pvt. seed company & 1 \\
\hline \multicolumn{5}{|c|}{ Non-Indian Carica papaya cultivars } \\
\hline Category & Accession name & & Source & Number of accessions \\
\hline South African cultivar & Hortus Gold & Dioecious & Pvt. seed company & 1 \\
\hline Hawaiian cultivar & Kapoho & Gynodioecious & USDA & 1 \\
\hline Hawaiian cultivar & Solo Papaya 109 & Gynodioecious & USDA & 1 \\
\hline Hawaiian cultivar & Sunrise Solo & Gynodioecious & USDA & 1 \\
\hline F1 hybrid Tainung series & Taiwan & Gynodioecious & Pvt. seed company & 1 \\
\hline F1 hybrid Tainung series & Taiwan Red lady & Gynodioecious & USDA & 1 \\
\hline American cultivar (Florida) & Waimanalo & Gynodioecious & Pvt. seed company & 1 \\
\hline \multicolumn{5}{|c|}{ Other Caricaceae species } \\
\hline Category & Accession name & & Source & Number of accessions \\
\hline Highland papaya & Vasconcellea goudotiana & Dioecious & USDA & 1 \\
\hline Highland papaya & Vasconcellea microcarpa & Dioecious & USDA & 1 \\
\hline Highland papaya & Vasconcellea parviflora & Dioecious & USDA & 1 \\
\hline Highland papaya & Vasconcellea pubescens & Dioecious & USDA & 1 \\
\hline
\end{tabular}


Table 3 Category, cultivar name, source and number of accessions used for this study (Continued)

\begin{tabular}{|c|c|c|c|c|}
\hline Highland papaya & Vasconcellea stipulata & Dioecious & USDA & 1 \\
\hline Highland papaya & Vasconcellea quercifolia & Dioecious & USDA & 1 \\
\hline Related genus & Jacaratia spinosa & Dioecious & USDA & 1 \\
\hline
\end{tabular}

ICAR: Indian Council of Agricultural Research, IIHR: Indian institute of Horticultural Research, OUAT: Orissa University of Agriculture and Technology, TNAU: Tamil Nadu Agriculture University, USDA: United States Department of Agriculture.

had been reflected hence no null alleles were produced but some rare alleles have been manifested. The Indian Carica papaya accessions have a long history of domestication and were bred by various plant breeders to suit the varied Indian agro-climatic conditions (Ram, 2005). Within the Indian territory these accessions had undergone indiscriminate cross-pollination along with high degree of wind and insect pollination up to a distance of several kilometers leading to the production of numerous local mixtures everywhere in the country (Prest, 1955). They also had diverse parents which include genotypes from within the country as well as genotypes from South East Asia and North America (Ram, 2005). This variation combined with spontaneous mutations had perhaps made the genetic base for the Indian genotypes much wider than the non-Indian Carica papaya accessions and the accessions of Vasconcellea sp. and Jacaratia spinosa included in this study. Off course further insight into the inherent genetic diversity of these and other Indian papaya accessions and their comparisons to a larger number of nonIndian accessions is required to form a decisive statement on the genetic nature of Indian Carica papaya accessions.

\section{Materials and methods}

Plant materials

The germplasm set in this study included 1 accession each from 27 Indian and 7 non-Indian commercially popular Carica papaya cultivars, 1 accession each of Vasconcellea goudotiana, Vasconcellea microcarpa, Vasconcellea parviflora, Vasconcellea pubescens, Vasconcellea stipulata and Vasconcellea quercifolia and 1 accession of South American tree species Jacaratia spinosa. The collection was maintained at the experimental farm of Acharya J.C. Bose Biotechnology Innovation Centre, Bose Institute at Madhyamgram. Fully expanded fourth leaf from the top was used as plant material for genomic DNA isolation.

Table 4 Name, BAC-End sequence name, motif, reference, forward and reverse primer and annealing temperature of the SSR markers used

\begin{tabular}{|c|c|c|c|c|c|c|}
\hline Name & BAC-End sequence name & Motif & Reference & Forward Primer & Reverse Primer & $\mathrm{T}^{\circ} \mathrm{C}$ \\
\hline SP 1 & Pbac -102C-06.T1.G06 & $(\mathrm{TTC}) 5 /(T \mathrm{TC}) 9$ & Chun et al., (2006) & TGCAACAGAAATAAAAACAGCA & GACGTGGACGAGCTCTGTGT & 51 \\
\hline SP 3 & Pbac -14D-B01.t1_009.ab1 & $(A C)_{9}$ & Chun et al., (2006) & CACCAACAAGTTCCTTGGGT & TGCATGCATGTGTGTGGATA & 57 \\
\hline SP4 & Pbac -15C-B06.t1.B06.ab1 & $(\mathrm{AT})_{9}$ & Chun et al., (2006) & TGCTCATAAAGTGATGGAGGT & TGGCGACCATTTAAACAACA & 55.5 \\
\hline SP5 & Pbac -15C-E11.y1.E11.ab1 & $(A C)_{9}$ & Chun et al., (2006) & TTGGCTCAAATTCAGGCTा & GCGGCTTCTGGATCTGATAA & 56 \\
\hline SP6 & Pbac -16C-C10.y1.C10.ab1 & $(\mathrm{AT})_{9}$ & Chun et al., (2006) & CTTGCACCGAACCCTAAAAG & CATGAAAAACACATGCCTGC & 57 \\
\hline SP7 & Pbac -16A-B08.y1_063.ab1 & $(\mathrm{AAT})_{7}$ & Chun et al., (2006) & CAGTTGTAGGGGTTGGTGGT & GTCCACAAATCAGAGCCCAT & 59 \\
\hline SP8 & Pbac -2B-F07.Y1_061 & $(\mathrm{ATT}) 7$ & Chun et al., (2006) & CAAATCATGTTGGTCTGCGT & GCTCAGCGGCTATITTTGAC & 57 \\
\hline SP9 & Pbac -28D-E10.t1_081.ab1 & $(\mathrm{AC}) 10$ & Chun et al., (2006) & TCAATGAGCCCCTCAATITC & ATGGATGGATTCAGCCGTTA & 56 \\
\hline SP10 & Pbac-3C-H06.t1_057.ab1 & $(C T) 20$ & Chun et al., (2006) & CGACGTCGTITTCTCCTTC & CACACATCGTGGGTTGAAGT & 58 \\
\hline SSPA 1 & Pbac-102A-H04.Y1.h04.scf & $(A) 21$ & Eustice et al., (2008) & TCATCGTCTTCAACCTGTAGC & ATCGACCTCCTCCATCACAC & 61 \\
\hline SSPA 2 & Pbac-102C-01.T1.H01.scf & (AT)12 & Eustice et al., (2008) & ACCAGAGTGGACCCAGTAGC & TGTTCACGTAAGGCATCCTG & 61 \\
\hline SSPA 3 & Pbac-102D-A11.T1.A11.scf & $(A G) 10$ & Eustice et al., (2008) & CGAAGCAAAACTTCTCAGCC & TCTCAATTTCCATITCCGC & 58 \\
\hline SSPA 4 & Pbac-10B-F10.T1_089.ab1 & (ТTC) 10 & Eustice et al., (2008) & GTGCAAGTCTCTCGAGTCCC & CTTGCTITGCACTITCAGG & 61 \\
\hline SSPA 5 & Pbac-10C-c04.y1_023.ab1 & $(\mathrm{TA}) 11$ & Eustice et al., (2008) & CACGAACAACTGTCACCCAC & TCAAGACCTITGCATGATGG & 61 \\
\hline SSPA 6 & Pbac-10C-G06.t1_049.ab1 & $(\mathrm{TA}) 12$ & Eustice et al., (2008) & GCTGCATCGACATITACGAA & TCAAGCCTGAGGAATCTGCT & 59 \\
\hline SSPA 7 & Pbac-1D-F03.y1_028.ab1 & $(A G) 24$ & Eustice et al., (2008) & TTCAAATCTITTTCGCACCC & TCAACAGCTTCGTTGACCAG & 59 \\
\hline SSPA 8 & Pbac-21C-F01.t1F01.scf & (AT)12 & Eustice et al., (2008) & TGTCTCAGCATATCCACCCA & ATGGCCTITGGAACATCAG & 60 \\
\hline SSPA 9 & Pbac-25ZB-F01.y1_012.ab1 & $(\mathrm{AAG}) 10$ & Eustice et al., (2008) & GCAGAAGCCAACAGCTCTCT & AGATCTAGCAGCCGCCATAA & 61 \\
\hline SSPA 10 & Pbac-28A-B03.t1_026.ab1 & $(\mathrm{TTC}) 7$ & Eustice et al., (2008) & AGGAATGCCCTCCATGTAAA & AGGAATGCCCTCCATGTAAA & 59 \\
\hline SP 3 & Pbac -14D-B01.t1_009.ab1 & $(A C)_{9}$ & Chun et al., (2006) & CACCAACAAGTTCCTTGGGT & TGCATGCATGTGTGTGGATA & 57 \\
\hline
\end{tabular}

Name - Identifiers given to each marker in our laboratory $\mathrm{T}^{\circ} \mathrm{C}$ - Annealing temperature as determined during our experimentation. 
The category, cultivar name, source and number of accessions use in this study for each cultivar are given in Table 3.

\section{Isolation of genomic DNA and PCR amplification}

Genomic DNA isolation was done according to the method of Walbot (1988). PCR amplification of this DNA was done with 20 SSR markers. Ten of the markers used were designed by Chun et al. (2006) and the rest by Eustice et al. (2008), were used to study the genetic diversity. The name, BAC-End sequence name, motif, reference, forward and reverse primer and annealing temperature of those markers are given in Table 4. DNA amplification was carried out in $25 \mu \mathrm{l}$ volumes using $200 \mu \mathrm{l}$ thin-walled PCR tubes (Axygen, USA) in a MJR thermal cycler. Each reaction mixture contained $1 \mu \mathrm{l}$ of genomic DNA (100 ng), $0.5 \mu \mathrm{l}$ of each of the two primers (at a concentration of $10 \mathrm{pmole} / \mu \mathrm{l}), 2.5 \mu \mathrm{l}$ of a $10 \mathrm{X}$ PCR buffer, $0.75 \mu \mathrm{l}$ of a $50 \mathrm{mM} \mathrm{MgCl}$ solution, $0.25 \mu \mathrm{l}$ of a $2.5 \mathrm{mM}$ dNTP mixture, $0.2 \mu \mathrm{l}$ ( 1 unit) of a 5 unit/ $\mu \mathrm{l}$ Taq DNA polymerase and $19.3 \mu \mathrm{l}$ of PCR-grade water. The temperature profile used for PCR amplification was $97^{\circ} \mathrm{C}$ for 5 mins, $55-60^{\circ} \mathrm{C}$ (as necessary in accordance to Table 4) for $2 \mathrm{~min}$; followed by 35 cycles of $1 \mathrm{~min}$ at $95^{\circ} \mathrm{C}, 1 \mathrm{~min}$ at $55-60^{\circ} \mathrm{C}$ and $2 \mathrm{~min}$ at $72^{\circ} \mathrm{C}$. The final extension was at $72^{\circ} \mathrm{C}$ for $10 \mathrm{~min}$.

\section{Polyacrylamide Gel electrophoresis}

The PCR products were resolved by native polyacrylamide gel electrophoresis (PAGE) following the protocol given by Sambrook et al. (1989) in a 6\% gel in vertical electrophoresis tank (gel size of $16 \mathrm{~cm} \times 14 \mathrm{~cm}$, Biotech, India) with Tris-Acetate-EDTA buffer at $150 \mathrm{~V}$ supplied by a power pack. The gel, after electrophoresis, was stained with ethidium bromide $(5 \mu \mathrm{g}$ of $\mathrm{EtBr}$ in $200 \mathrm{ml}$ of Tris-Borate-EDTA buffer) washed thoroughly with double distilled water and photographed using a Gel Documentation System (Biorad, USA).

\footnotetext{
Allele scoring

Under UV light a cluster of 2 to 5 discrete bands (stutter) was apparent in the stained gels for most of the markers. The size (in nucleotides) of the most intensely amplified band for each microsatellite marker was determined using the software Quantity One (Biorad, USA), based on the migration of the band relative to molecular weight size markers (100 bp DNA ladder SibEnzyme) included in the gel (Cho et al. 2000). The molecular weights of the Carica papaya cultivar SunUp, as derived from previous experiments (Papaya BAC end sequence library developed by the Hawaii Agricultural Research Center and the Center for Genomcis, Proteomics, and Bioinformatics Research Initiative) was used as a molecular weight reference for each marker. The band with the lowest molecular weight for each SSR marker was assigned allele number 1 and the
}

progressively heavier bands were assigned incrementally. For the individual markers, the presence of an allele in each of the germplasms was recorded as " 1 " and the absence of an allele was denoted as "0" (Cho et al. 2000). Null alleles were assigned when no amplification product was generated (Callen et al. 1993). When an allele was found in less than $5 \%$ of the germplasms under study, it was designated as rare (Jain et al. 2004).

\section{Genetic diversity analysis using SSR profiles}

A 1/0 matrix was constructed for each marker using the information of presence or absence of alleles and was used to calculate genetic similarities among the accessions according to Jaccard (1908) using NTSYS-pc software package (version 2.02e) (Rohlf 1997). Using pairwise similarity matrix of Jaccard's coefficient, a phylogenetic tree was made by unweighted pair-group method of arithmetic average (UPGMA) and neighbor-joining (NJoin) module of the NTSYS-pc. Support for clusters was evaluated by bootstrap analysis using WinBoot software (Yap and Nelson 1995) through generating 1,000 samples by resampling with replacement of characters within the combined $1 / 0$ data matrix. The average polymorphic information content (PIC) was calculated for each marker in accordance with the method Anderson et al. (1997).

\section{One way ANOVA}

One way ANOVA was done to test whether the means of the PIC values for the total set of germplasms, and for the three categories (Indian and non Indian Carica papaya accessions and the accessions of Vasconcellea species and Jacaratia spinosa) were significantly different or not. The software SPSS 10.0 was used for the purpose.

\section{Competing interests}

The authors declare that they have no competing interest.

\section{Authors' contributions}

SS: Procured the germplasms, the SSR primers, did all the experiments pertaining to DNA. extraction, PCR, PAGE, collected data and sequenced polymorphic bands. BD: Was involved in data analysis and drafting the manuscript. Dr. MP: Did the dendrogram and bootstrap analysis. Dr. PA: Was involved with the conception of the work. Dr. TKG: Was involved with the conception of the work and gave the final approval to the version of the manuscript that is being sent for consideration for publication. All authors read and approved the final manuscript.

\section{Authors' information}

SS - Senior Research Fellow, Department of Horticulture, Institute of Agricultural Science, University of Calcutta, 35, Balligunge Circular Road, Kolkata 700029, West Bengal, India.

BD - Senior Research Fellow, Division of Plant Biology, Bose Institute, Main Campus, 93/1 A.P.C. Road, Kolkata 700009, West Bengal, India.

MP - Scientist National Institute of Plant Genome Research (NIPGR), Aruna Asaf Ali Marg, New Delhi 110067, India

PA - Assistant Professor, Department of Horticulture, Institute of Agricultural Science, University of Calcutta, 35, Balligunge Circular Road, Kolkata 700029, West Bengal, India.

TKG - Associate Professor, Division of Plant Biology, Bose Institute, Main Campus, 93/1 A.P.C. Road, Kolkata 700009, West Bengal, India. 


\section{Acknowledgements}

The authors wish to thank United States Department of Agriculture, Indian Council of Agricultural Research (Tripura), Indian Institute of Horticultural Research, Orissa University of Agriculture and Technology and Tamil Nadu Agriculture University for contributing the Caricaceae accessions. They also wish to thank the Department of Science and Technology for providing the research funding through Bose Institute and for providing the fellowship to Basabdatta Das. Thanks are also due to the University of Calcutta for providing fellowship to Samik Sengupta.

\section{Author details}

'Division of Plant Biology, Bose Institute, Main Campus, 93/1 A.P.C. Road, Kolkata, West Bengal 700009, India. ${ }^{2}$ Department of Horticulture, Institute of Agricultural Science, University of Calcutta, 35, Balligunge Circular Road, Kolkata, West Bengal 700029, India. ${ }^{3}$ National Institute of Plant Genome Research (NIPGR), Aruna Asaf Ali Marg, New Delhi, 110067, India.

Received: 4 April 2013 Accepted: 23 July 2013

Published: 26 July 2013

\section{References}

Anderson PA, Lawrence GJ, Morrish BC, Ayliffe MA, Finnegan EJ, Ellis JG (1997) Inactivation of the Flax rust resistance gene $\mathrm{M}$ associated with loss of a repeated unit within the leucine rich repeat coding region. Plant Cell 9:641-651

Asudi GO, Ombwara FK, Rimberia FK, Nyende AB, Ateka EM, Wamocho LS, Shitanda D, Onyango A (2010) Morphological diversity of Kenyan papaya germplasm. African J of Biotech 9:8754-8762

Badillo VM (1993) Caricaceae. Segundo esquema. Revista de la Facultad de Agronomía de la Universidad Central de Venezuela, Alcance 43, Maracay, Venezuela, $\mathrm{p} 111$

Badillo VM (2000) Carica L. vs. Vasconcellea St.-Hil. (Caricaceae) con la rehabilitación de este último. Ernstia 10:74-79

Bremer K, Chase MW, Stevens PF (1998) An ordinal classification for the families of flowering plants. Ann Mo Bot Gard 85:531-553

Callen DF, Thompson AD, Shen Y, Phillips HA, Richards RI, Mulley JC, Sutherland GR (1993) Incidence and origin of "null" alleles in the (AC) n microsatellite markers. Am J Hum Genet 52:922-927

Cho YG, Ishii T, Temnykh S, Chen X, Lipovich L, Park WD, Ayres N, Cartinhour S, McCouch SR (2000) Diversity of microsatellites derived from genomic libraries and GenBank sequences in rice (Oryza sativa L.). Theor Appl Genet 100:713-722

Chun WJL, Yu Q, Hou S, Skelton RL, Jones MR, Lewis KLT, Murray J, Eustice M, Guan P, Agbayani R, Moore PH, Ming R, Presting GG (2006) Analysis of papaya BAC end sequences reveals first insights into the organization of a fruit tree genome. Mol Gen Genomics 276:1-12

Drew RA, O'Brien CM, Magdalita PM (1998) Development of interspecific Carica hybrids. Acta Hortic 461:285-292

Eustice M, Qingyi Yu CW, Lai S, Hou J, Thimmapuram L, Liu M, Alam PH, Moore GG, Presting R, Ming R (2008) Development and application of microsatellite markers for genomic analysis of papaya. Tree Genet and Genomics 4:333-341

FAO (2009) Statistical databases of the Food and Agriculture Organization of the United Nations., www.fao.org/statistics

Hamilton RA, Ito PJ (1968) Sunrise Solo-a different coloured Solo papaya. Cir Hawaii Agric Exp Stat Univ 69:5

Jaccard P (1908) Nouvelle recherches sur la distribution florale. Bulletin de la Socie'te' Vaudoise des Sciences Naturelles 44:223-270

Jain S, Jain RK, McCouch SR (2004) Genetic analysis of Indian aromatic and quality rice (Oryza sativa L.) germplasm using panels of fluorescently-labeled microsatellite markers. Theor Appl Genet 109:965-977

Kim MS, Moore PH, Zee F, Fitch MMM, Steiger DL, Manshardt RM, Paull RE, Drew RA, Sekioka T, R. Ming R (2002) Genetic diversity of Carica papaya as revealed by AFLP markers. Genome 45:503-512

Kulsekaran M (1984) Papaya. Directory of Germplasm Collection, Tropical Fruits IBPGR, 133

Kyndt T, Van Droogenbroeck B, Haegeman A, Roldán-Ruiz I, Gheysen G (2006) Cross-species microsatellite amplification in Vasconcellea and related genera and their use in germplasm classification. Genome 49:786-798

Liu Z, Moore PH, Ma H, Ackerman CM, Ragiba M, Yu Q, Pearl HM, Kim MS, Charlton JW, Stiles JI, Zee FT, Paterson AH, Ming R (2004) A primitive Y chromosome in papaya marks incipient sex chromosome evolution. Nature 427:22-26

Ma H, Moore PH, Liu Z, Kim MS, Yu Q, Fitch MM, Sekioka T, Paterson AH, Ming R (2004) High-density linkage mapping revealed suppression of recombination at the sex determination locus in papaya. Genetics 166:419-436

Manshardt RM, Wenslaff TF (1989) Interspecific hybridization of papaya with other species. J Amer Soc Hort Sci 114:689-694

Ming R, Moore PH, Zee F, Abbey CA, Ma H, Paterson AH (2001) Construction and characterization of a papaya BAC library as a foundation for molecular dissection of a tree-fruit genome. Theor Appl Genet 102:892-899

Nakasone HY, Paull RE (1998) Tropical Fruits. CAB International, Wallingford, UK, 445

Oliveira EJ, Amorim VBO, Matos ELS, Costa JL, Castellen MS, Pádua JG, Dantas JLL (2010a) Polymorphism of microsatellite markers in papaya (Carica papaya L). Plant Mol Bio Reporter 28:519-530

Oliveira EJ, Silva AS, Carvalho FM, Santos LF, Costa JL, Amorim VO, Dantas JLL (2010b) Polymorphic microsatellite marker set for Carica papaya $L$ and its use in molecular-assisted selection. Euphytica 173:279-287

Prest RL (1955) Unfruitfulness in papaya. Qd Agric J 81:144-148

Purseglove JW (1974) Tropical Crops: Dicotyledons. Longman, London, pp 45-51

Ram M, Majumder PK, Singh BN (1985) Papaya germplasm collection in India. IBPGR Newsletters 9:6-7

Ram M (2005) Papaya. Indian Council of Agricultural Research, New Delhi India, pp 19-45

Ram M, Sharma SD (1996) Uniformity trials on papaya. Int. Conf. on Trop. Fruit, Malaysia, pp 50-51

Rodman JE, Karol KG, Price RA, Sytema KJ (1996) Molecules, morphology and dahlgren's expanded order Capparales. Syst Bot 21:289-307

Rohlf FJ, NTSYSpc (1997) Numerical Taxonomy and Multivariate Analysis System. Vol. 2.0. Exeter Software, Setauket, New York, p 33

Sambrook J, Fritsch EF, Maniatis T (1989) Molecular cloning: A laboratory manual, 2nd edn. Cold Spring Harbour Laboratory Press, New York

Singh AK, Bajpai A, Singh A (2006) Classification of morpho-agronomic variability in papaya for developing elite cultivar. Acta Horticulturae 851: II International Symposium on Papaya

Sondur SN, Manshardt RM, Stiles JI (1996) A genetic linkage map of papaya based on randomly amplified polymorphic DNA markers. Theor Appl Genet 93:547-553

Storey WB (1969) Papaya. In: Ferwerda FP, Wit FH (eds) Outlines of Perennia Crop Breeding in the Tropics. Veenman \& Zonen NV. Wageningen, The Netherlands, pp 389-408

Van Droogenbroeck B, Breyne P, Goetghebeur P, Romeijn-Peeters E, Kyndt T, Gheysen G (2002) AFLP analysis of genetic relationships among papaya and its wild relatives (Caricaceae) from Ecuador. Theor Appl Genet 105:289-297

Villarreal L, Dhuique-Mayer C, Dornier M, Ruales J, Reynes M (2003) Evaluation de l'intérêt du babaco (Carica pentagona Heilb.). Fruits 58:39-52

Walbot V (1988) Preparation of DNA from single rice seedling. Rice Genet Newsl 5:149-151

Walsh PS, Fildes NJ, Reynolds R (1996) Sequence analysis and characterization of stutter products at the tetranucleotide repeat locus vWA. Nucleic Acids Res 24:2807-2812

Xiao J, Li J, Yuan L, McCouch SR, Tanksley SD (1996) Genetic diversity and its relationship to hybrid performance and heterosis in rice as revealed by PCR based markers. Theor Appl Genet 92:637-643

Yap IP, Nelson R (1995) Win Boot: A programm for performing boot strap analysis of binary data to determine the confidence limits of UPGMA-based dendrograms. IPRI Discussion Paper series

Yu QY, Navajas-Pérez R, Tong E, Robertson J, Moore PH, Paterson AH, Ming R (2008) Recent origin of dioecious and gynodioecious $Y$ chromosomes in papaya. Tropical Plant Biology 1:49-57

doi:10.1186/2193-1801-2-345

Cite this article as: Sengupta et al:: A comparative survey of genetic diversity among a set of Caricaceae accessions using microsatellite markers. SpringerPlus 2013 2:345. 